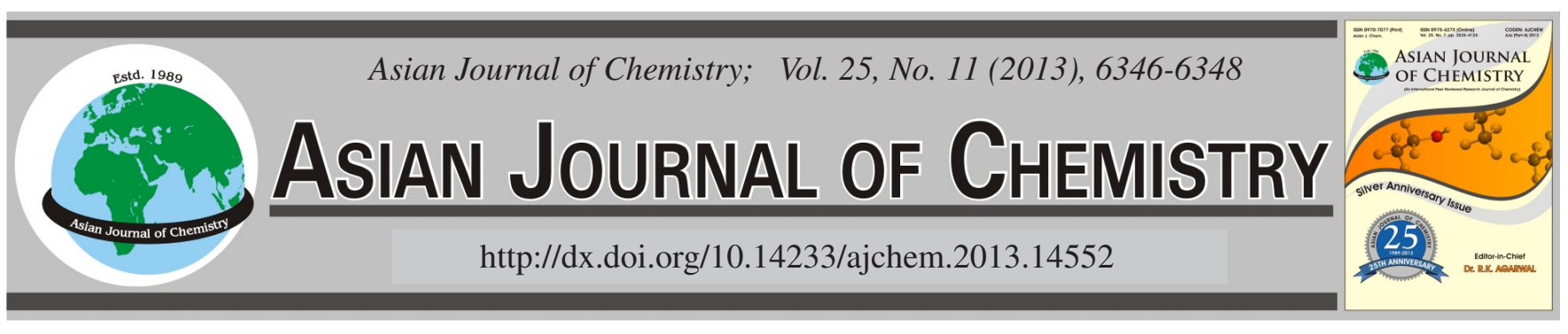

\title{
Variation in Amino Acid Content Among Three Aloe Species
}

\author{
Yong Kyoung Kim ${ }^{1}$, Seung Yeon Suh ${ }^{1}$, Md. Romij Uddin ${ }^{1}$, Yeon Bok Kim ${ }^{1}$, \\ Haeng Hoon KIm², SAng Won LeE ${ }^{3}$ and SAng Un PARK ${ }^{1, *}$
}

\begin{abstract}
${ }^{1}$ Department of Crop Science, College of Agriculture \& Life Sciences, Chungnam National University, 99 Daehak-ro, Yuseong-gu, Daejeon, 305-764, Republic of Korea

${ }^{2}$ Department of Well-being Resources, Sunchon National University, 413 Jungangno, Suncheon, Jeollanam-do 540-742, Republic of Korea ${ }^{3}$ Herbal Crop Research Team, National Institute of Horticultural \& Herbal Science, RDA, Eumseong-gun, Chungcheongbuk-do 369-873, Republic of Korea
\end{abstract}

*Corresponding author: Fax: +82 42822 2631; Tel: +82 42821 5730; E-mail: supark@cnu.ac.kr

(Received: 10 September 2012;

Accepted: 10 May 2013)

AJC-13469

\begin{abstract}
Aloe species are well known as medicinal plants and are also used in various commercial products. Here, we have analyzed the amino acid contents of three Aloe species (Aloe arborescens, A. vera and A. saponaria) and have discussed the differences in amino acid levels among these three species. A total of 24 and 23 amino acids were detected in A. vera and A. saponaria, respectively, whereas only 17 amino acids were detected in A. arborescens. A. vera had high levels of ammonia, aspartic acid, glutamic acid, serine, arginine, valine, alanine, whereas A. saponaria contained the highest levels of ammonia, glutamic acid, aspartic acid, valine and alanine. In particular A. vera contained 11 times more $\gamma$-amino butyric acid than A. arborescens did. A. vera contained a greater overall concentration of amino acids than the other species did. The mean concentrations of phosphoserine and taurine were higher in A. arborescens than in the other Aloe species. In conclusion, among these Aloe species, A. vera had the highest total amino acid concentration and the greatest variation in amino acid contents.
\end{abstract}

Key Words: Amino acid, Aloe, Aloe vera, Aloe arborescens, Aloe saponaria

\section{INTRODUCTION}

Aloe is a very common genus, comprising approximately 400 species of shrubby succulent plants occurring naturally in Africa of which Aloe vera is the most common and well known species ${ }^{1,2}$. Although Aloe species have been used throughout history for medicinal purposes, only a few of the 400 species are actually used traditionally as herbal medicines.

In particular, the mucilaginous gel from the parenchymatous cells in the leaf pulp of $A$. vera has been used since early times for various curative purposes ${ }^{3}$ and in recent years extensive research has been carried out on the health-promoting and medicinal properties of this plant. It has shown a variety of biological and pharmacological activities, including promotion of wound healing; hypoglycemic or antidiabetic effects and antiinflammatory, anticancer, immunomodulatory and gastroprotective properties; as well as antifungal, antityrosinase and antioxidant activities ${ }^{4-8}$.

A. vera and A. arborescens are the most widely cultivated species of Aloe worldwide ${ }^{9}$ and is also commonly used as a medicinal plant. These species have also been reported to have antidiabetic, antitumor, antimicrobial and antifungal activities ${ }^{10-13}$.
A. saponaria is another variety used worldwide and is also known as soap Aloe or African Aloe. This species has a lower aloin content than other Aloe varieties and therefore has a less bitter taste than other Aloe species ${ }^{14}$. The ethanol extract of $A$. saponaria displays antioxidant, antinociceptive and antiinflammatory activities ${ }^{15}$.

In order to further understand the differences between various species of Aloe studies have focused on identifying the primary and secondary metabolites in the different species. However, to date, research on the amino acid content of Aloe species has been very limited. For instance, Sotelo et al. ${ }^{16}$ previously reported the analysis of amino acids in the edible flower of A. vera while Nicolson ${ }^{17}$ reported an analysis of the amino acids in the nectar of 16 different Aloe species. The aim of the present work was to compare the amino acid content of three Aloe species by using HPLC.

\section{EXPERIMENTAL}

The leaves of two year-old Aloe plants, belonging to $A$. arborescens, A. saponaria and $A$. vera were used for chemical analysis. The fresh samples were stored in-sealed clear polyethylene plastic bags at $-80{ }^{\circ} \mathrm{C}$ until further use. The 
samples were freeze dried at $-80{ }^{\circ} \mathrm{C}$ in brown paper bags for $72 \mathrm{~h}$ and the dried samples were ground into a fine powder (40-mesh) by using a mill.

Extraction and analysis of free amino acids: The amino acid extraction and analysis methods were performed as described by Kim et al. ${ }^{18}$. Amino acids were extracted from freeze-dried plant tissues $(1 \mathrm{~g})$ with $30 \mathrm{~mL}$ of $70 \%$ ethanol at $80{ }^{\circ} \mathrm{C}$ for $20 \mathrm{~min}$; this step was repeated 3 times. After evaporating the ethanol, the residual water phase $(30 \mathrm{~mL})$ was mixed with ethyl ether $(30 \mathrm{~mL})$ by using a separation funnel. After separation, the water phase was freeze-dried. The extract was resuspended in $3 \mathrm{~mL}$ of $0.02 \mathrm{~N} \mathrm{HCl}$ and filtered using a 0.45 $\mu \mathrm{m}$ syringe filter.

The amino acids in the extract were identified using an amino acid analyzer (HITACHI L-8900, Japan) equipped with an HITACHI HPLC column packed with the ion-exchange resin No. $2622 \mathrm{PF}(4.6 \mathrm{~mm} \times 60 \mathrm{~mm}$ ) and a UV detector (VIS1, $570 \mathrm{~nm}$; VIS2, $440 \mathrm{~nm}$ ). Wako L-8500 buffer solutions PF-1, PF-2, PF-3, PF-4 and RG were used. Twenty microliters of each sample was injected and identification was performed using the ninhydrin reagent set (Wako Chemical Inc., Japan). Sample preparation and analysis were repeated three times.

\section{RESULTS AND DISCUSSION}

Amino acid contents were determined for samples of three species of Aloe collected from Korea and 24 different amino acids were found to be present in varying proportions. More specifically, a total of 24 and 23 amino acids were detected in the extracts from A. vera and A. saponaria, respectively, while only 17 different amino acids were identified in the extract from $A$. arborescens. The following 8 amino acids were present in both A vera and A. saponaria but not in A. arborescens: threonine (Thr), isoleucine (Ile), leucine (Leu), tyrosine (Tyr), phenylalanine (Phe), $\beta$-aminoisobutyric ( $\beta$-AiBA), histidine (His) and arginine (Arg).

In $A$. arborescens, phosphoserine (P-ser), carnosine (Car) and aspartic acid (Asp) were detected at much higher levels than other amino acids (Table-1). In A. saponaria, ammonia $\left(\mathrm{NH}_{3}\right)$, glutamic acid (Glu), Asp, valine (Val) and alanine (Ala) were particularly abundant, while the levels of the other amino acids were lower (Table-1). A. vera contained the highest amount of the following amino acids: $\mathrm{NH}_{3}$, Asp, serine (Ser), Glu, Arg and Val (Table-1).

Moreover, A. vera contained the highest amount (90.15 $\mu \mathrm{mol} / \mathrm{g}$ D.W.) of $\gamma$-amino butyric acid (GABA), which was approximately 11 times more than that present in $A$. arborescens (Table-1). Most of the amino acids (Ala, $\beta$-AiBA, Arg, Asp, ethanolamine, glycine [Gly], His, lysine (Lys), Ser, Thr, Tyr) were detected in A. vera at higher levels than in the other species (Table-1). In total, the greatest concentration of amino acids was detected in A. vera (2792.65 $\mu \mathrm{mol} / \mathrm{g}$ D.W.). The amino acid, hydroxylysine (Hylys) is present only in the extract of $A$. arborescens. Carnosine levels were almost similar among the three Aloe species, while, Ala, proline (Pro) and Val levels were similar in A. vera and A. saponaria.

Aloe is frequently used for a variety of purposes orlwide. Compared to the other Aloe species, A. vera is the most commonly used Aloe speciesin the commercial and pharmaceutical
TABLE-1

AMINO ACID CONTENT IN THREE Aloe SPECIES

\begin{tabular}{|c|c|c|c|}
\hline & A. arborescens & A. saponaria & A. vera \\
\hline P-Ser & $129.83 \pm 10.01$ & $98.74 \pm 4.25$ & $136.08 \pm 1.77$ \\
\hline $\mathrm{Tau}$ & $32.33 \pm 2.61$ & $19.40 \pm 0.86$ & $27.49 \pm 0.18$ \\
\hline Asp & $102.15 \pm 0.99$ & $219.51 \pm 13.33$ & $281.31 \pm 1.55$ \\
\hline Thr & - & $37.48 \pm 3.18$ & $104.73 \pm 8.23$ \\
\hline Ser & $33.97 \pm 2.51$ & $76.48 \pm 9.48$ & $268.59 \pm 21.8$ \\
\hline Glu & $19.44 \pm 1.03$ & $328.51 \pm 17.61$ & $222.73 \pm 10.28$ \\
\hline Gly & $5.17 \pm 0.94$ & $16.97 \pm 2.64$ & $69.55 \pm 2.72$ \\
\hline Ala & $51.03 \pm 1.15$ & $122.78 \pm 7.05$ & $125.58 \pm 3.77$ \\
\hline$\alpha-\mathrm{ABA}$ & $7.39 \pm 0.46$ & - & $17.50 \pm 0.71$ \\
\hline Val & $24.27 \pm 0.12$ & $143.43 \pm 9.85$ & $163.27 \pm 3.41$ \\
\hline Ile & - & $43.38 \pm 2.93$ & $26.24 \pm 1.5$ \\
\hline Leu & - & $42.56 \pm 3.51$ & $20.96 \pm 0.8$ \\
\hline Tyr & - & $30.68 \pm 4.58$ & $37.90 \pm 0.25$ \\
\hline Phe & - & $53.16 \pm 4.36$ & $43.58 \pm 1$ \\
\hline$\beta$-Ala & $4.63 \pm 0.3$ & $37.64 \pm 3.26$ & $51.64 \pm 1.38$ \\
\hline$\beta$-AiBA & - & $11.40 \pm 1.36$ & $20.51 \pm 0.38$ \\
\hline$\gamma$-ABA & $7.99 \pm 0.26$ & $71.00 \pm 3.88$ & $90.15 \pm 0.74$ \\
\hline $\mathrm{EOHNH}_{2}$ & $15.20 \pm 0.6$ & $54.03 \pm 3.3$ & $64.25 \pm 0.87$ \\
\hline $\mathrm{NH}_{3}$ & $93.74 \pm 4.2$ & $440.28 \pm 27.93$ & $492.07 \pm 5.63$ \\
\hline Hylys & $41.03 \pm 1.51$ & - & - \\
\hline Lys & $7.55 \pm 0.83$ & $78.30 \pm 5.33$ & $114.34 \pm 2.89$ \\
\hline His & - & $18.33 \pm 1.6$ & $38.91 \pm 2.78$ \\
\hline Car & $111.02 \pm 4.71$ & $117.45 \pm 1.96$ & $124.20 \pm 11.16$ \\
\hline Arg & - & $51.57 \pm 2.74$ & $215.45 \pm 14.38$ \\
\hline Pro & $17.85 \pm 7$ & $32.26 \pm 6.75$ & $35.64 \pm 0.05$ \\
\hline Total & $704.58 \pm 39.23$ & $2145.36 \pm 141.71$ & $2792.65 \pm 98.23$ \\
\hline \multicolumn{4}{|c|}{$\begin{array}{l}\text { The values represent the mean } \pm \mathrm{SD}(\mathrm{n}=3) \text {. } \\
\text { P-Ser, Phosphoserine; Tau, Taurine; Asp, Aspartic acid; Thr, } \\
\text { Threonine; Ser, Serine; Glu, Glutamic acid; Gly, Glycine; Ala, } \\
\text { Alanine; } \alpha \text {-ABA, } \alpha \text {-Amino butyric acid; Val, Valine; Ile, Isoleucine; } \\
\text { Leu, Leucine; Tyr, Tyrosine, Phe, Phenylalanine; } \beta \text {-Ala, } \beta \text {-Alanine; } \beta \text { - } \\
\text { AiBA, } \beta \text {-amino isobutyric acid; GABA, Gamma amino butyric acid; } \\
\text { EOHNH }{ }_{2} \text {, Ethanolamine, } \mathrm{NH}_{3} \text {, Ammonia; Hylys, Hydroxylysine; Lys, } \\
\text { Lysine; His, Histidine; Car, Carnosine; Arg, Arginine; Pro, Proline. }\end{array}$} \\
\hline
\end{tabular}

fields. These species have been the best studied of all Aloe species, many researchers contend that it has more useful chemical properties than do the other species. However, other Aloe species have also currently attracted interest for different chemical properties and medicinal uses and indeed $A$. arborescens and $A$. saponaria have similar and in some respect, a higher content of metabolites as compared with $A$. vera. In this study, we analyzed the amino acid content of these 3 species of Aloe by HPLC. During amino acid analysis, a few non-protein amino acids were also detected, including $\gamma$-amino butyric acid, which is an inhibitory neurotransmitter in the central nervous system and has been implicated as a potential factor in human disease ${ }^{19}$.

Aloe vera has many more effective amino acids than other species. $\beta$-Alanine is known as the rate-limiting precursor for carnosine $\mathrm{e}^{20,21}$. Harris et al..$^{22}$ discovered that the carnosine levels in skeletal muscle may increase by $60 \%$ or more after ingesting $\beta$-Ala for 2-4 weeks. Other studies have demonstrated that $\beta$-Ala supplementation may further improve both endurance performance and reduce subjective feelings of fatigue during training ${ }^{23,24}$.

Amino acids are not only the building blocks for proteins that are involved in every process that occurs in the body but also play a role in metabolism. Although hundreds of different amino acids exist in nature, only approximately 2 dozen of these are vital for human nutrition ${ }^{25,26}$. The body can produce approximately half of the amino acids and must obtain the 
rest from food. The different species of Aloe are an easily accessible and constitute an economically viable potential source of various amino acids.

\section{REFERENCES}

1. A.D. Klein and N.S. Penneys, J. Am. Acad. Dermatol., 18, 714 (1988).

2. C. Ulbricht, J. Armstrong, E. Basch, S. Basch, S. Bent, C. Dacey, S. Dalton, I. Foppa, N. Giese, P. Hammerness, C. Kirkwood, D. Sollars, C.S. Tanguay and W. Weissner, J. Herb Pharmacother, 7, 279 (2007).

3. D. Grindlay and T. Reynolds, J. Ethnopharmacol., 16, 117 (1986).

4. T. Reynolds and A.C. Dweck, J. Ethnopharmacol., 68, 3 (1999).

5. B.K. Vogler and E. Ernst, Br. J. Gen. Pract., 49, 823 (1999).

6. O.M. Grace, M.S. Simmonds, G.F. Smith and A.E. van Wyk, J. Ethnopharmacol., 119, 604 (2008).

7. A. Surjushe, R. Vasani and D.G. Saple, Indian J. Dermatol., 53, 163 (2008)

8. A. Feily and M.R. Namazi, G. Ital. Dermatol. Venereol., 144, 85 (2009).

9. Y. Gutterman and E. Chauser-Volfson, Biochem. Syst. Ecol., 28, 825 (2000).

10. M.I. Ali, N.M. Shalaby, M.H. Elgamal and A.S. Mousa, Phytother. Res., 13, 401 (1999).

11. A. Kodym and T. Bujak, Pharmazie, 57, 834 (2002).

12. G.Z. Jin, H.J. Quan, J. Koyanagi, K. Takeuchi, Y. Miura, F. Komada and S. Saito, Cancer Lett., 218, 15 (2005).

13. H. Beppu, K. Shimpo, T. Chihara, T. Kaneko, I. Tamai, S. Yamaji, S. Ozaki, H. Kuzuya and S. Sonoda, J. Ethnopharmacol., 103, 468 (2006).
14. J. Li, T. Wang, Z. Shen and Z. Hu, Acta Botan. Sin., 45, 594 (2003).

15. E.A. Yoo, S.D. Kim, W.M. Lee, H.J. Park, S.K. Kim, J.Y. Cho, W. Min and M.H. Rhee, Phytother. Res., 22, 1389 (2008).

16. A. Sotelo, S. Lopez-Garcia and F. Basurto-Pena, Plant Foods Hum. Nutr., 62, 133 (2007)

17. S.W. Nicolson, J. Chem. Ecol., 33, 1707 (2007).

18. Y.K. Kim, H. Xu, N.I. Park, H.O. Boo, S.Y. Lee and S.U. Park, J. Med. Plants Res., 3, 897 (2009).

19. M. Watanabe, K. Maemura, K. Kanbara, T. Tamayama and H. Hayasaki, Int. Rev. Cytol., 213, 1 (2002).

20. W. Derave, M.S. Ozdemir, R. Harris, A. Pottier, H. Reyngoudt, K. Koppo, J.A. Wise and E. Achten, J. Appl. Physiol., 103, 1736 (2007).

21. C.A. Hill, R.C. Harris, H.J. Kim, B.D. Harris, C. Sale, L.H. Boobis, C.K. Kim and J.A. Wise, Amino Acids, 32, 225 (2007).

22. R.C. Harris, M.J. Tallon, M. Dunnett, L. Boobis, J. Coakley, H.J. Kim, J.L. Fallowfield, C.A. Hill, C. Sale and J.A. Wise, Amino Acids, 30, 279 (2006).

23. J.R. Hoffman, N.A. Ratamess, A.D. Faigenbaum, R. Ross, J. Kang, J.R. Stout and J.A. Wise, Nutr. Res., 28, 1 (2008).

24. A.E. Smith, A.A. Walter, J.L. Graef, K.L. Kendall, J.R. Moon, C.M. Lockwood, D.H. Fukuda, T.W. Beck, J.T. Cramer and J.R. Stout, J. Int Soc. Sports Nutr., 6, 5 (2009).

25. G.S. Gilani, C. Xiao and N. Lee, J. AOAC Int., 91, 894 (2008).

26. D.J. Millward, D.K. Layman, D. Tomé and G. Schaafsma, Am. J. Clin. Nutr., 87, 1576 (2008). 